\title{
The Use of Multiple Representations in Undergraduate Physics Education: What Do we Know and Where Do we Go from Here?
}

\author{
Nuril Munfaridah ${ }^{1,2^{*}}$, Lucy Avraamidou ${ }^{1}$, Martin Goedhart ${ }^{1}$ \\ ${ }^{1}$ Institute for Science Education and Communication, University of Groningen, Nijenborgh 7, 9747 AG Groningen, \\ NETHERLANDS \\ 2 Department of Physics, Faculty of Mathematics and Natural Sciences, Universitas Negeri Malang, Jl. Semarang No.5 Malang, \\ 65145, INDONESIA
}

Received 19 August 2020 - Accepted 9 November 2020

\begin{abstract}
Using multiple representations (MR) such as graphs, symbols, diagrams, and text, is central to teaching and learning in physics classrooms. While different studies have provided evidence of the positive impact of the use of MR on physics learning, a comprehensive overview of existing literature on the use of MR in physics education, especially at the undergraduate level, is missing. This manuscript addresses this gap in the literature by reporting on the outcomes of a systematic review study that aimed to provide an overview of the existing knowledge base, to identify gaps in the knowledge base, and to propose future research about the use of MR in the context of undergraduate physics education. For the purpose of this study, we reviewed 24 empirical studies published between 2002 and 2019 in scientific, peer-reviewed journals in the context of undergraduate physics education. The outcomes of this review study are discussed under these themes (a) In what ways does the use of MR in instruction support student learning? (b) What kinds of representations do students use? (c) What difficulties do students face in using MR? (d) What is the relation between students' use of MR and students' problem-solving skills? and, (e) What is the added value of technology integration in teaching with MR? We identify gaps in the existing knowledge base, and we propose future research directions in these three areas: (a) Exploring the use of MR in university physics textbooks; (b) Blending of different kinds of MR; and, (c) The use of virtual reality applications.
\end{abstract}

Keywords: multiple representations, physics education, systematic review

\section{INTRODUCTION}

Physics is of utter importance in university science education. However, teaching and learning physics remains a challenging task. An approach to addressing this challenge is the use of multiple representations (MR), which refers to the combination of different modes of representation, and aims at communicating abstract concepts in more concrete ways and making them broadly accessible. As Treagust et al. (2018) discussed, different modes of representation, as for example, analogies, diagrams, graphs, cartoons, formulas, text, simulations, and gestures can be used to communicate scientific concepts.
The use of MR in learning environments is nowadays commonplace as teachers often use representations to make complex and abstract concepts accessible through different forms of visualization, and research shows that the use of MR might enhance student learning (Klein et al., 2018; Korff \& Rebello, 2012; Maries \& Singh, 2018; McPadden \& Brewe, 2017; Podolefsky \& Finkelstein, 2006; Rosengrant et al., 2009; Susac et al., 2017, 2019; Sutopo \& Waldrip, 2014). However, research also shows that students have difficulties in relating and integrating the representations and translating information between them (Bollen et al., 2017; Maries et al., 2017).

Situated in the context of undergraduate physics education, the purpose of this systematic review study is to provide an overview of the existing knowledge base

(c) 2021 by the authors; licensee Modestum. This article is an open access article distributed under the terms and conditions of the Creative Commons Attribution License (http://creativecommons.org/licenses/by/4.0/).

\.munfaridah@rug.nl (*Correspondence) $\$ l.avraamidou@rug.nl $\$ m.j.goedhart@rug.nl 


\section{Contribution to the literature}

- This paper synthesizes the literature on how multiple representations (MR) can be used in undergraduate physics education and in physics education research (PER). Our most important conclusions:

- MR might serve as a powerful learning strategy in physics education and has a positive impact on undergraduate students' understanding of physics concepts.

- There is no evidence in the literature that one kind representation is better than another in supporting students develop their understandings of physics concepts.

- Students use different kinds of representations and the combination of kinds of representations has the potential to support student problem solving and consequently their development of conceptual understanding.

- Students face different difficulties in using MR during the learning process, especially in switching between kinds of representations.

- Computer-based representations can support students' physics learning, as for example, conceptual understanding and representational competence.

- This paper identifies gaps in the existing knowledge base and proposes as future research directions:(a) Exploring the use of MR in university physics textbooks; (b) Blending of different kinds of MR; and (c) Using virtual reality applications.

about the use of MR, to identify gaps in this knowledge base, and to propose future research directions. In reviewing related literature, it becomes clear that the use of MR is central in research about problem solving (Docktor \& Mestre, 2014). As Mathewson (1999) argued, one of the most commonly used ways of communicating scientific ideas is by means of visual representations, which also plays an important role in teaching physics (Chen \& Gladding, 2014). Moreover, Hill and Sharma (2015) recommended the use of representations, such as words, graphs, equations, and diagrams, for the purpose of supporting student learning. In discussing the role of MR in physics teaching and learning, Opfermann et al. (2017) pointed out that MR have a great potential in supporting student learning of physics concepts because students learn easier when problems include MR, hence, the use of MR can maximize the results of students' learning processes.

While various studies have provided evidence of the positive impact of the use of MR on students' physics learning, a comprehensive overview of existing literature on the use of MR in undergraduate physics education is missing. Our purpose in this systematic review study is to address this gap. In aiming to do so, we critically synthesize the literature in the area of MR and undergraduate physics and physics education. For the purpose of this study, we reviewed empirical studies published in the past seventeen years (2002-2019) in prominent scientific, peer-reviewed journals in the context of undergraduate physics education. The time frame of the past 17 years was selected because we aimed at providing a review of contemporary research. Based on the outcomes of the review we identify knowledge gaps in existing literature and we propose future research directions. In what follows, we offer first a definition of MR for the purpose of establishing a background understanding of how researchers have defined and used MR. Following on that, we discuss the methods we used and the procedures we followed to carry out this review study. We then discuss the outcomes of the review study, we identify gaps in the existing knowledge, and we conclude with a set of recommendations for future research.

\section{DEFINING MULTIPLE REPRESENTATIONS}

Multiple representations have been conceptualized and used in different ways by researchers. A generally accepted definition is the one provided by Tytler et al. (2007), who stated:

MR refer to the capacity of scientific discourse to represent the same concepts or processes in different modes (e.g., verbal, visual, mathematical, graphical) while multi-modal representation refers to the integration of different modes to represent scientific processes, findings, and scientific explanations (p. 314).

According to Ainsworth (1999), representations can generally be divided into two categories: (a) external representations, which are in a form that can be seen by others, such as pictures, text narrations, graphs, symbols, etc., and (b) internal representations or mental models, which act out as structural analogies of situations or processes. Ainsworth (2008) argued that MR might have three distinct roles in learning. The first one is that MR serve a complementary role given that using texts and pictures together will complement each other. This role is connected to different ways of learning. For example, by using MR, students can choose what the best way is for them to learn, but they can also combine representations that can make learning easier. Students can use texts, pictures, graphs, tables and other 
representations. This means that one problem can be solved with the use of several representations. Another role that MR might play in learning can be actualized by employing common representations and by using inherent properties of one (common) representation to develop the interpretation of the second representation (uncommon). Finally, MR might play a role in supporting the development of a deeper conceptual understanding. This role relates to the ways in which MR might enhance abstraction, extension, and relation. The students who have a deep understanding of certain concepts can transform one kind of representation into another kind of representation (Ainsworth, 1999).

External representations refer to "the knowledge and structure in the environment, as physical symbols, objects, or dimensions" while internal representations refer to "the knowledge and structure in memory, as propositions, productions, schemas, neural networks, or other forms" (Zhang, 1997, p. 180). Information in external representations can be processed by perceptual operation and refers to information that is directly perceived. Instead, information in internal representations refers to information retrieved directly from working memory that involves cognitive operation. Hence, through memorization, an internal representation can be transformed to an external representation. A review of related literature, shows that most studies used the term "multiple representation" to refer solely to external representations given the difficulty in accessing and evaluating internal representations while Gilbert (2010) used the term "representation" to refer to both external, visible representations as well as internal representations. In this review study, we adopt Tytler et al's (2007) conceptualization of multiple representations and we include studies that examine external representations. However, we also include two studies that examined internal representations which were made externally available, and, hence essentially transformed to external representations.

In discussing research related to the use of MR in education, Opfermann et al. (2017) argued that researchers ought to pay attention to the following: text, picture, and the individual learner because the design of MR does not always provide benefits to all students and not in the same way. As the researchers argued, the text used in MR should be simple, well-arranged, and concise in order to provide a meaningful explanation. Moreover, several factors have to be considered when designing an MR-embedded learning environment, such as the following: students' individual differences, prior knowledge, and cognitive load because these directly affect how students use representations. In addition, the use of logical pictures in MR is also of importance. As researcher have reported, using a picture as a visual representation in the learning process enhanced student learning (Podolefsky \& Finkelstein, 2006; Van Heuvelen \& Zou, 2001).

In the next section, we describe the methods used to carry out this review study aiming to synthesize the existing knowledge base on the use of MR in physics education.

\section{METHODS}

In carrying out this review study, we started with an advanced search in online library databases with the use of the following search words: "multiple representations" and "physics"; "representations" and "physics"; "multiple representations in physics". As a result, we identified publications that included books, journal articles, theses, book chapters, and conference proceedings. Following that, we selected only articles published in peer-reviewed scientific journals, which were included in the three largest databases: (a) Web of Science; (b) Eric; and (c) Google Scholar.

The articles were selected based on the following criteria: (a) the article was published in the past 17 years (2002-2019); (b) the article concerns an empirical inquiry about the use of MR in teaching and learning physics at the undergraduate university level; (c) the article describes the use of MR explicitly as a learning approach or investigated variable; and (d) the quality of the journal based on the criteria of quartiles (i.e., quartile rank 1 and 2) provided by https://www.scimagojr.com/. Furthermore, we included only those articles that treated MR as the combination of at least two kinds of representations, as for example, the combination of mathematics equations, verbal, diagrams, pictures, graphs, etc. This resulted in the selection of 24 articles as described in Figure 1.

We acknowledge three distinct limitations of the design of this study in terms of purpose, the use of databases, and the use of the specific timeframe. First, we acknowledge that despite the fact that the three databases used are considered the largest ones, it is likely that we have missed out important contributions that are not included in these databases. In addition, we acknowledge limitation associated with the timeframe, which probably excludes important studies published prior to 2002 and after 2019. Lastly, this systematic review study focused solely on studies done at the undergraduate level and hence fails to provide a more comprehensive synthesis of the knowledge base that cuts across age and education levels.

\section{THE ROLE OF MULTIPLE REPRESENTATIONS IN PHYSICS EDUCATION}

In the next section we synthesize the findings of the 24 empirical studies (Appendix 1) that were selected for an in-depth review for the purpose of responding to the 


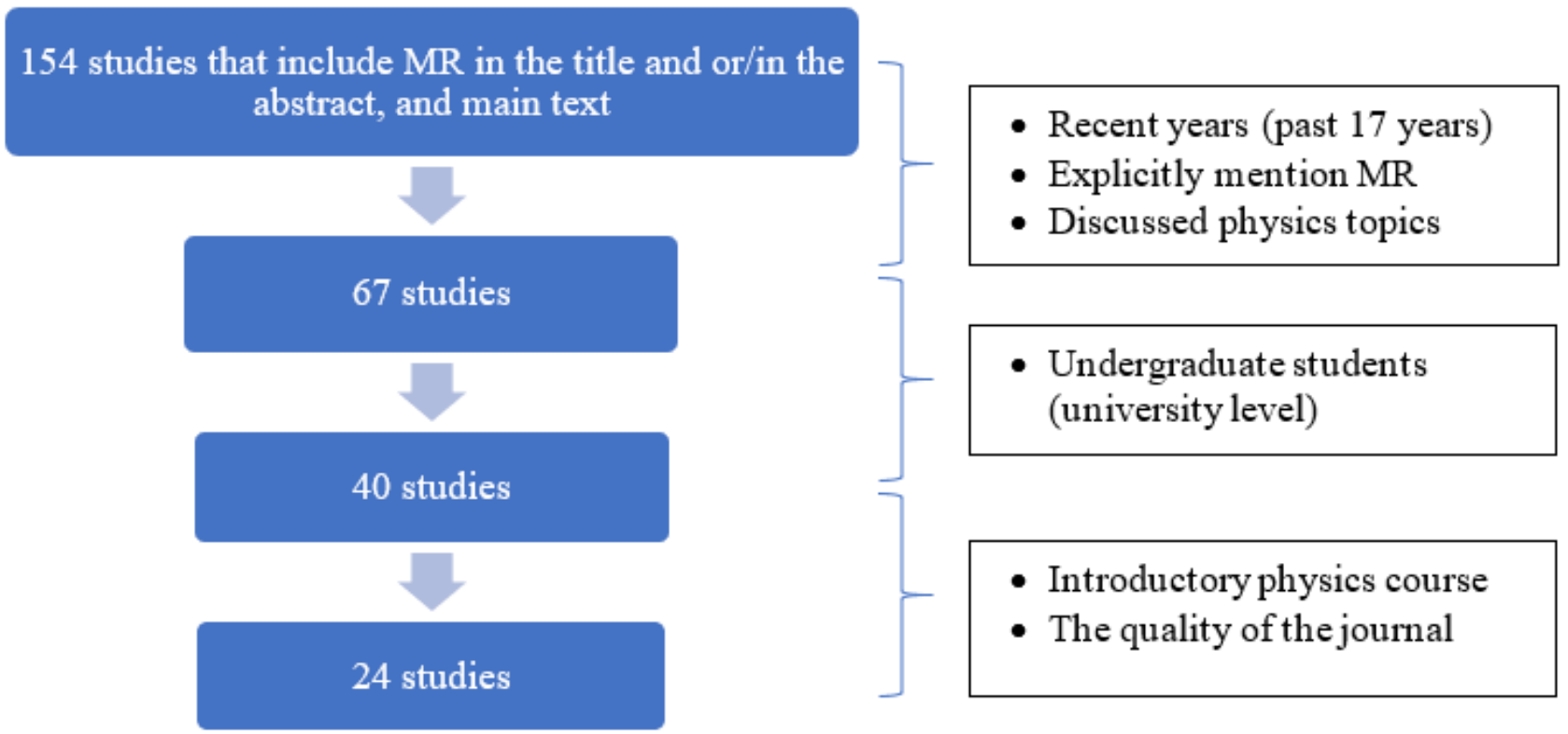

Figure 1. The selection process of manuscripts

Table 1. Themes of Reviewed Articles

\begin{tabular}{ll}
\hline Themes & Literature \\
\hline In what ways does the use of MR in instruction & Sutopo and Waldrip (2014) \\
support student learning? & Podolefsky and Finkelstein (2006) \\
& Susac, Bubic, Martinjak, Planinic, and Palmovic (2017) \\
& Rosengrant, Van Heuvelen, and Etkina (2009) \\
& McPadden and Brewe (2017) \\
& Korff and Rebello (2012) \\
& Maries and Singh (2018) \\
& Klein, Viiri, Mozaffari, Dengel, and Kuhn (2018) \\
& Susac, Bubic, Planinic, Movre, and Palmovic (2019) \\
\hline What kinds of representations do students use? & Kuo, Hull, Gupta, and Elby, (2013) \\
& Chiou and Anderson (2010) \\
& Fredlund, Airey, and Linder (2012) \\
\hline What difficulties do students face in using MR? & Ibrahim and Rebello (2013) \\
\hline Whatlen, Van Kampen, Baily, Kelly, and De Cock (2017) \\
and students' problem-solving skills? & Maries, Lin, and Singh (2017) \\
& Kohl and Finkelstein (2005) \\
& Kohl and Finkelstein (2006) \\
& Meltzer (2005) \\
\hline What is the added value of technology integration & De Cock (2012) \\
in teaching with MR? & Susac, Bubic, Kazotti, Planinic, and Palmovic (2018) \\
& Zacharia and De Jong (2014) \\
& Magana, Serrano, and Rebello (2019) \\
& Hill, Sharma, and Johnston (2015) \\
\hline
\end{tabular}

question: What do we know about the use of $M R$ in undergraduate physics teaching and learning? The manuscripts were analyzed based on the following aspects: (a) aim of the study, research questions, information about the participants; (b) information about the context of the study; (c) how MR was conceptualized; (d) methods used; and (e) findings. The findings of the analysis are presented next under the main themes phrased as questions (Table 1), in which these 24 studies fit.

\section{In What Ways does the Use of MR in Instruction Support Student Learning?}

Sutopo and Waldrip (2014) used MR in a seven-week long intervention and explored its impact on 24 preservice teachers' conceptual understanding of mechanics and their reasoning ability. The study used a mixed-methods, embedded experimental design. Data were collected with pre- and post-tests on students' conceptual understanding, and students' responses when they discussed problems during the intervention. 
The participants constructed claims about the physics problems and provided evidence to support those during the learning process. They were also involved in discussions and representational manipulations to solve the problems. In order to examine the impact of the intervention, the researchers measured the students' reasoning abilities through pre- and post-tests. The results showed that the students' reasoning ability increased significantly. In addition, the results showed that the students' conceptual understandings of mechanics significantly improved. Lastly, the students' competence in mechanics shifted significantly from a competent level to mastery level. Based on this finding, the researchers concluded that the representational approach was successful in supporting students develop the ability to critique and evaluate data. However, what is missing in this study is an understanding of the cognitive processes students are engaged in during the processes of data evaluation.

An attempt to shed light on students' reasoning when engaged with MR is found in the study carried out by Podolefsky and Finkelstein (2006) who examined how students used analogies in the context of an introductory physics course through post-tests. Specifically, the researchers examined where the use of different analogies led to different student reasoning and whether analogies supported the generation of inferences. The study was carried out in two calculus-based introductory physics courses taught in two different semesters $(n=249$ and $n=353)$ that combined large lectures and tutorials. The researchers grouped students into three large groups in each semester: the first group used sound analogy, the second group used string analogy, and the third group did not use any analogy. Each group completed three parts of tutorials: (a) the students in the group of both sound analogy and string analogy were given a tutorial including pictorial representations of the form of wave propagation on a string and as a sound wave; (b) each group solved the same problem which included a picture of electromagnetic waves; and (c) each group carried out a post-test. The results showed that the representations could cue students to focus on different characteristics of electromagnetic waves. Following that, the researchers developed an assessment representation to examine the possible mechanisms of how students used the analogies. The students were asked to choose pictorial representations based on analogies on a string and sound waves and to justify their choice. The findings of this study showed a correlation between students' representation choices and their reasoning abilities. Specifically, the findings showed that the use of analogies supported the generation of inferences about the propagation of electromagnetic waves. In addition, the findings showed that representations played a key role in the use of analogy, as they supported students in focusing on specific characteristics of physical phenomena.

Similar findings were revealed in a study carried out by Susac et al. (2017), which, however, used graphical representations of data instead of analogies. The researchers hypothesized that graphical data representations would improve student understanding of measurement and reduce the cognitive load of measurement analysis, compared with numerical representation data. To examine this hypothesis, the researchers used two kinds of methods in obtaining data from students: a paper-and-pencil test and eye-tracking measurements. The paper-and-pencil test, administered to 101 undergraduate physics students, used eight multiple-choice items. Half of the participants $(n=49)$ were given a test with a graphical data representation, and the remaining participants were given the test without a graphical data representation. During the test, two researchers observed and assessed students' responses. Through an analysis of eye-tracking data, the researchers found that students spent less time in the area of interest of the numerical data because the graphical representation of data helped them to visualize the data, as the students said. These results point to that graphical representations may be beneficial for data processing and data comparison because they can reduce working memory load and support students in understanding measurement data analysis.

A study carried out by Rosengrant et al. (2009) provided evidence that the use of $\mathrm{MR}$ as a teaching strategy can help students enhance their understanding of physics concepts. This study aimed to examine why students use representations and whether those students who use them are more successful than the students who do not make use of representations. The researchers used free-body diagrams (FBDs) as one kind of representation in solving physics problems in a class of 500 students enrolled in a two-year physics-based algebra course. Data were collected from students' multiple-choice exams in the first and second year. In analyzing the data, the researchers compared the number of correct answers and evaluated the diagrams developed by the students in the problem-solving process. The outcomes of the analysis showed that the students who used diagrams correctly performed significantly better than the students who did not draw diagrams adequately. In the second year of the study, the researchers collected data through in-depth interviews with six students from three different achievement levels who were enrolled in the traditional environment in this course which served as a control group. The students were asked to solve one problem presented in verbal representation. In analyzing the results of the interviews, the researchers categorized students' responses into four different categories related to the students' comments on why they used representations: to understand the problem, to solve the problem, to evaluate their work, and to check 
the consistency between kinds of representations. The findings of this study showed that students who used representations correctly were significantly more successful in obtaining the right answer for the problem than the students who did not use representations. Moreover, the majority of students used diagrams to solve exam problems even if they did not receive credit for drawing diagrams. The high-achieving students used diagrams not only to solve the problems but also to evaluate their work. The low-achieving students used diagrams only for the purpose of solving the problem. These findings are important because they shed light on the impact of the use of diagrams on students' understandings as well as reasons why students might choose to use representations.

Another study investigating the use of diagrams in physics learning has been carried out by Maries and Singh (2018) who examined the role of different interventions related to diagram representation. The participants in this study were 111 students who enrolled in an algebra-based introductory physics course. The students were divided in three recitation groups based on the following conditions of using representations: (a) the diagram was given by the researchers; (b) the diagram was drawn by students; and (c) no clue was provided about the use of the diagram. The students were free to choose between these options based on their convenience. The researchers provided two electricity problems and developed a rubric as guidance in scoring the students' work. The findings showed that the students who were asked to draw diagrams were more likely to draw a productive diagram while the students who were provided with diagram representations performed significantly worse than the students in the two other groups.

In order to explore the possible reasons for this result, the researchers conducted a follow-up study, which involved 23 students who were enrolled in an equivalent algebra-based introductory physics course. The researchers used two think-aloud protocols and observational interviews to collect data, which took place after the students completed the course. The analysis of the data showed that the students who were provided with the diagram spent less time in trying to understand and analyze the problems. The students tended to focus on selecting which equation could be used to solve the problems right away and did not make use of the diagram. These findings, as the researchers concluded, point to the fact that employing diagrams that are not very complex might have a detrimental effect and hinder instead of enhance learning.

Another study exploring the role of diagrams on supporting students' conceptual understanding has been carried out by Susac et al. (2019) who made use of eye tracking technology. The materials used in this study were six multiple-choice questions related to energy concepts. The participants were 60 preservice physics teachers who were divided into two experimental groups. The researchers used six multiple-choice questions for data collection. Three questions were presented with diagrams, while the rest of the questions were presented without diagrams in one experimental group. The other experimental group was provided with diagrams for the other three questions, while the rest of the questions was provided without diagrams. To perform eye-tracking measurement, the researcher defined three areas of interest for each question: the text of the problem, the multiple-choice answers, and the diagram. The results showed that the use of supportive diagrams was directly related to the correctness of the students' responses. In addition, through analysis of eyetracking data, the researchers found that the students who were provided with supportive diagrams spent less time in reading the text, which might imply that presenting information in both representations (text and diagrams) does not necessarily have an impact on students' problem-solving success.

McPadden and Brewe (2017) adopted a different approach towards the use of MR in physics teaching through the use of an integrated conceptual model consisting of equations, graphs, pictures, a motion map, and a word description. In doing so, they aimed to investigate different groups of students' representation choices in introductory physics. To do that, the researchers examined both what individual representations students chose as well as the average number of representations that each student used. The first group included students who were new to modeling instruction in the electromagnetic course $(n=28)$ named "new students", and the second group included students who had already received modeling instruction in the previous course (mechanics) named "returning students" $(n=30)$. The researchers designed a modified card-sort survey in order to examine the students' choice of representations consisting of 25 questions: 13 questions on electricity and 12 questions on mechanics. The survey was administered before and after the modeling instruction class of electricity and magnetism. The data analysis included a comparison between: (a) pre- and post-semester, and (b) new and returning students. The results revealed significant differences between the scores on the mechanics presurvey and post-survey questions, and between new and returning students. For all questions combined, the group of "new students", in contrast to the group of "returning students", on average, increased their representation choices per question from $13.4 \%$ to $19.6 \%$, which amounts to a gain of one representation per question. Another set of the results showed that the group of "returning students" made use of higher-level representations when solving problems in mechanics more often than the group of "new students". However, the group of "returning students" did not show significant growth in their representation ability of 
electricity topics unlike the group of "new students". This finding is significant because it indicates that the two groups of students had different experiences in the class, which highlights the importance of drawing upon students' experiences in previous courses when designing a new course.

Adopting a qualitative research approach, Korff and Rebello (2012) investigated the impact of a set of specially designed lessons on integration. The researchers conducted a case study with one studentparticipant to examine if and how these lessons supported the participant in learning about integration in mechanics. Seven lessons (two-hours long each) focused on one-dimensional integrals for displacement, work, momentum, moment of inertia, and center of mass. The lessons involved equation, graph and verbal representations. The female participant was enrolled in a calculus-based physics course. During the implementation of the lessons, the researchers recorded videos of the student and the instructor for the purpose of examining the participant's use of MR as well as her understanding of mechanics. The data analysis showed that the participant was able to conceptualize and explain integrals using MR through several layers, such as the quantity, product, and sum layers. The findings of this study provide evidence about the value of the use of MR in supporting the development of conceptual understanding of integrals in the context of mechanics.

Klein et al. (2018) investigated the effectiveness of two strategies involving representations in enhancing students' conceptual understanding of electromagnetism. The first one was the derivative strategy, which is based on graphical interpretation, and the other one was the integral strategy, which is based on the flux concept. To examine how students employed these two strategies, the researchers used eye tracking by discriminating between correct and incorrect answers and between best performers and worst performers. This study involved 41 physics students who were enrolled in an introductory electromagnetism course. The materials used in data collections were: (a) pre-test with true-false and open-response items; (b) instruction pages; (c) vector field plots; (d) interviews; and (e) eye tracking. Following a pre-test, the students were asked to solve a problem involving both strategies in the two instructional periods. In the first period, 20 students solved the problems with the derivative strategy, and 21 students solved the problems with the integral strategy. In the second period, the strategy was changed for both groups of students. The last part of the data collection included an interview during which the students were asked to solve a problem using whatever strategy they wanted. Saccadic direction analysis was used to analyze the eye movement data for the derivative strategy, which implies vertical and horizontal saccades when the vector field is being looked at. The outcomes of the analysis showed that there was not a single "best strategy" for qualitatively judging the divergence of the vector field. Instead, they concluded that both strategies have their own characteristics and advantages and as such they serve complementary roles in supporting learning.

Collectively, the findings of the studies synthesized in this section provide evidence that MR might serve as a powerful learning strategy in physics education and has a positive impact on undergraduate students' conceptual understanding of physics concepts. Despite the fact that evidence drawn from this synthesis illustrates that specific representations (i.e., analogies, diagrams, graphical representations) can support undergraduate students in problem solving, there is no evidence that speaks directly to the question of whether one representation is better than another in supporting students develop conceptual understandings of physicsrelated concepts. Instead, different representations might be used for different purposes and also depending on students' prior experience with the use of a specific kind of representation.

\section{What Kinds of Representations Do Students Use?}

A review of related literature shows that during the problem-solving process, students use several kinds of representations as one way of making their thinking visible and communicating their ideas (Lehrer \& Schauble, 2000). Generally, students combine both conceptual reasoning (i.e., related to verbal representation) and equations (i.e., related to mathematical/symbolic representations). Problem solving in physics is supported by selecting equations followed by explaining the meaning of the equations to examine whether the solution is correct. Kuo et al. (2013) argued that such an approach, combining equations and verbal representation, can help students in the problemsolving process. In their case study, they explored how students blended conceptual and mathematical reasoning in the problem-solving process. The participants of the study were 13 students enrolled in a calculus-based, introductory physics course. Semistructured interviews were designed and carried out to probe the use of equations during problem solving. More specifically, the researchers designed several prompts (i.e., Velocity Equation and Two Ball Problems) to find out whether students were able to blend conceptual and mathematical reasoning. In the first part of the data analysis, the researchers focused their attention to the responses of two students - "Alex" and "Pat" - who were selected because they had very different responses. In the second part of the data analysis, the researchers analyzed 11 other students' responses to explore whether they used blended processing to find the solution or gave explanations of the equation that combined with a conceptual schema. The problemsolving process followed by Pat was rated as being more sophisticated than the problem-solving process followed by Alex. Unlike Alex, Pat used symbolic forms, which 
blend symbolic and conceptual knowledge in his solution. From analyzing the 11 students' responses, the researchers found that students used either a symbolic form-based explanation of the velocity equation or a blended processing shortcut on the Two Balls Problem. Based on these results, the researchers argued that blending conceptual and symbolic reasoning has the potential to support student learning.

Another set of studies have examined the kinds of representations that students use when they engage in problem-solving tasks. For example, Chiou and Anderson (2010) examined the relationship between students' mental models and their explanations about heat conduction. The researchers conceptualized mental models as cognitive representations that become external through the use of analogies about heat transfer. Data, which included verbal, drawings, and written responses, were collected through in-depth clinical interviews with 30 senior undergraduate physics students. The data analysis of the pictorial representations illustrated that students produced the following process analogies of heat transfer: marching, flooding, gradient, gradient-marching, and gradientflooding. In addition, the findings illustrated that the students' ontological beliefs were directly related to their conceptualizations of phenomena or mental models. More specifically, the researchers divided students' ontological beliefs into three categories (i.e., substance, energy, and interaction) and each ontological category was associated with a different explanation of how heat is treated when it is transferred. This finding is important because it highlights the need to consider both the processes of analogy production and students' ontological beliefs when designing for learning with MR.

Fredlund et al. (2012) examined the potential of different representations in supporting students' understandings of the properties of light in an interactive learning session. As the researchers argued, the use of representations in physics which includes spoken and written language as well as gestures, plays a critical role in the effectiveness of the engagement and interactions between students. The participants of this study were three students who were given 30 minutes to construct an argument about the refraction of light. The problem-solving process alongside the explanations was video-recorded. The data were analyzed by developing a thematic pattern from representations that appeared during the discussion and problem-solving process by students. The researchers described spoken and written language, diagrams, equipment, mathematics, and gestures in a chronological order to create thematic patterns. The results showed that the kinds of representations that students used the most were ray diagrams, wave front drawings, mathematics symbols, speech, and gestures.

Ibrahim and Rebello (2013) examined the types of mental representations that 19 students used during the problem solving of different representational task formats in the context of a calculus-based physics course. Specifically, the researchers examined three kinds of representations: linguistic, symbolic, and graphical. The researchers provided participants with a series of unstructured tasks with three kinds of representations and obtained data from their responses during a problem-solving task related to kinetics and work; they also interviewed each student. The students' responses to the thematic interview questions were organized into the following categories: (a) representational format; (b) task requirement; and (c) problem-solving strategies. In analyzing the data, students' profiles were created based on Johnson-Laird's cognitive framework which included: (a) propositional mental representations series of symbols which are syntactic abstract structures, such as equations, numbers, definitions; (b) mental models - constructions of acts of perception and an analogical representation of real-world situations; and (c) mental images - construction from the observation and experiences of real-world. The results of this study revealed that most students worked at the level of 'propositional mental representation' in both topics. This study also indicated that it is possible that students' inability to relate and translate information when dealing with MR may be influenced by the types of cognitive structures when handling a single representation task format. This finding, as the researchers stated, raises the question why this kind of representation was used the most. Hence, further research is recommended for exploring the reasons associated with the predominance of students' use of mental representations when dealing with different representation task formats.

The outcomes of the studies synthesized in this section show that students use different kinds of representations and the combination or a series of kinds of representations has the potential to support student problem solving and consequently their development of conceptual understandings. For example, one of the studies reviewed here, exemplified the importance of blending of equations and verbal representations. Another study showed the value of the use of analogies and how that is directly related to students' ontological beliefs. The third study reviewed showed that the kinds of representations that students used were the following: ray diagrams, wave front drawings, mathematics symbols, speech, and gestures. Likewise, the outcomes of the fourth study reviewed here, revealed that students made use of mostly propositional mental representations, which includes symbols, equations, formulas, numbers, and definitions.

\section{What Difficulties Do Students Face in Using MR?}

A review of the literature indicates that students face different kinds of difficulties when using MR in physics. For example, in a study carried out in four universities 
in three different countries, Bollen et al. (2017) explored students' difficulties regarding interpreting, constructing and switching between different kinds of representations. The researchers defined representations as different formats used in physics problems and focused on students' representational fluency (i.e., the ability to construct or interpret representations as well as the ability to translate and switch between representations on demand) in a vector field, which can be expressed in symbolic and graphical representations. They designed the Vector Field Representations test (VFR) to identify students' difficulties and used individual semi-structured student interviews to collect the data from four universities in the three countries. The participants were 196 students who enrolled in physics, electronic engineering, and a preservice science teacher program. All participants had taken a course on electromagnetism. The analysis of the data showed that the difficulties in each representation (field vectors, field lines, and symbols) were related to the understanding of two characteristics: magnitude and direction. Specifically, the findings showed that many students faced the following difficulties: (a) struggling with vector addition; (b) failing to recognize the field line density as an indication of the magnitude of the field; (c) confusing characteristics of field lines and equipotential lines; and (d) choosing the appropriate coordinate system when writing out mathematical expressions of vector fields. The researchers concluded that most students in these four universities lacked representational fluency when interpreting and constructing field line diagrams.

In a similar study, Maries et al. (2017) investigated students' difficulties in translating between mathematical and graphical representations for electrostatics problems and the effect of scaffolding students' representational consistency, defined as "students ability to transform between mathematical and graphical representations" (p. 2). The researchers conducted two studies: (a) study 1 to identify students' representational consistency and possible reasons that could account for the common difficulties that students had, and (b) study 2 to design a two-level scaffolding to help students overcome these difficulties. The participants were 65 students in a calculus-based introductory physics course who were provided with a problem about Gauss's law in study 1, and seven students who were involved in think-aloud interviews. In study 1 , the researchers found that students had much difficulty in translating mathematical into graphical representations. The difficulties that researchers found are the following: (a) students did not consider the differences of the behaviour of the electric field in each region, and (b) students realized that the electric field had a different behaviour in each region, but they plotted it with their qualitative analysis instead of with the mathematical function. Based on the students' difficulties in study 1, a two-level scaffolding was developed for Study 2. The findings of Study 2 showed that scaffolding the development of mathematical expressions and graphical representations positively impacted students' performance in translating mathematical and graphical representations of Gauss's law. This finding is important as it offers insights into the importance of examining students' difficulties prior to the design of scaffolds that aim to address specific difficulties in using MR.

As the findings of these two studies reveal, even though MR provide an empowering learning tool or learning strategy, students face different difficulties in using MR during the learning process, especially in switching between kinds of representations.

\section{What is the Relation between Students' Use of MR and Students' Problem-Solving Skills?}

Kohl and Finkelstein (2005) examined students' competence to use different representational formats which refer to the many ways in which a particular concept or problem can be expressed. More specifically, the three main research goals of the study were to: (a) provide further evidence that students' performance varies across different representations (i.e., verbal, mathematics, graphical, and pictorial) of physics concepts with similar content; (b) show that providing students with a choice of representation format will change their performance; and (c) to examine students' choice and assessment of representations. The study was conducted in two algebra-based introductory physics classes $(n=546$ and $n=367)$ and included a combination of large-group lectures and small-group tutorials. The data included homework problems and quiz problems. The results showed that students' performance on physics problems varied with representational format. Most of the students were successful with the use of the mathematical format. However, the researchers also noticed that the correlation between the representation format and the performance depended strongly on the topic of the problem. To address the second goal, the researchers performed a comparison between students who received a quiz at random and the ones who were allowed to choose a quiz format based on the kind of representation used. If the students were allowed to choose a representational format, results varied: it influenced their performance positively under certain circumstances and negatively under other circumstances. To address the third goal, the researchers examined students' responses to questions (i.e., write a few sentences about why they chose the problem format). The analysis showed that students viewed mathematical and pictorial representations as dominant but also opposite; hence, most of them selected one of the two.

In order to examine how and when students' performance in terms of problem-solving varies with 
problem representation (i.e., verbal, mathematical, graphical, or pictorial), Kohl and Finkelstein (2006) carried out a study with 16 students who were enrolled in an introductory physics course. The researchers interviewed the students to examine how they solved the problems, and specifically, the strategies that they employed. The findings showed that students' strategies ranged from very diverse to very consistent when confronted with different representations, and the students who use more variation in their strategies performed more poorly than the ones who were consistent. These findings led the researchers to the conclusion that the effects of problem representation on problem-solving performance are complex and depends on various factors, such as topic, students' prior knowledge as well as the particulars of the representation.

A similar study was carried out by Meltzer (2005) to explore the impact of different kinds of representations on students' problem-solving performance. Five years of classroom data from 400 students were collected in an algebra-based general physics course. In the beginning of the course, the students were asked to complete a pretest which included two very similar Newton's third-law questions, of which one was presented in a verbal representation and the other in a diagrammatic representation with vector diagrams. Similar problems were provided in the post-test to know the consistency of participants' responses. The instruction between the pre-test and post-test was based on an interactive engagement approach. The evaluation of the students' responses showed that the proportion of correct answers on the verbal question was consistently higher than on the diagrammatic question. In addition, the pattern of incorrect responses to the questions differed consistently. Additional data were collected through four quizzes. Each quiz had four very similar questions posed in four representations: verbal, diagrammatic, mathematical/symbolic, and graphical. Based on the responses to both of the quizzes, the researcher compared the incorrect responses for each representation. The researcher found that there was a statistically significant difference in the Coulomb quiz (diagram versus graphical), but no significant differences were found between different representations in general. The researcher summarized the results in the following assertions: (a) some students provided inconsistent answers to the same question when it was asked using different representations; (b) specific difficulties were noted when using vector representations in the context of Newton's third law; (c) female students had slightly higher error rates on graphical questions in comparison with other representations; and (d) female students were also indicated having difficulties in electric circuit diagrams. The findings showed that the different students' difficulties in the class that emphasized MR's use could be considered substantial.

Similar results were produced in a study carried out by De Cock (2012) who examined whether students performed differently when solving a physics problem formulated in different representational formats (i.e., verbal, pictorial, graphical), and what kinds of problemsolving strategies they use depending on the representational format in which the problem is stated. This study involved 200 first-year students enrolled in a mandatory physics course as part of the pharmaceutical science program in three consecutive years. Multiplechoice test items were used in different representational formats, and the students had to provide explanations of their answers. The analysis of students' responses was conducted in two ways. First, the researcher counted the correct answers without considering the explanation provided. She then counted the correct answers in relation to the provided explanations, which showed a direct relation between the kind of representation used and students' problem-solving skills. The results of this study showed that the representational format affected students' performance on the tasks, which provides further evidence that specific, micro-level features of a representation can lead students to use a particular problem-solving strategy.

The kinds of problem-solving strategies employed by the students were also examined by Susac et al. (2018) who examined physics and non-physics students' understandings of graphs. Specifically, the researchers investigated the effects of concept, type of question, question context on students' scores, problem-solving strategies, and eye-tracking data. This study involved 90 students, of which half were physics majors and half were psychology majors. Most of the participants were fourth year university students, and their average age was 23 years. The researchers used following data sources: (a) eight multiple-choice test items; (b) four sets of isomorphic questions involving graphs in the context of physics (kinematics) and non-physics (finance); and (c) short questionnaire about similarity between the questions, the strategy in solving problem with graphs, and basic facts about the graph slope and the area under a graph. The participants solved the problems in the two steps. During the first step, eye-tracking data were collected. Next, the participants did a paper-pencil test and explained their answers. They were also answering questions from the short questionnaire that had been prepared. The results showed that physics students (graph experts) had much higher scores than psychology students (non-graph experts). Moreover, physics students solved qualitative and quantitative problems equally well, while psychology students performed better in solving qualitative problems than quantitative problems. All the students solved the problems related to the 'graph slope' better than the problems related to the 'area under the graph'. Another interesting finding 
of this study is that some of the physics students constructed a formula to solve the problem in the different context of physics which could be explained by the fact that physics students are more familiar with formulas than the psychology students, who mostly used common-sense strategies. The analysis of the eyetracking data, provided insights on the time spent by students to review information presented in the graph. Both physics and psychology students spent similar viewing times on the problems, which shows that both group of students had a similar cognitive load.

Summing up the findings of the studies reviewed in this section, it becomes clear that the kind of representation used impacts students' problem-solving success. However, missing remains an understanding of the ways in which various other factors and characteristics of the learning context relate to the use of representations (e.g., students' prior knowledge, students' familiarity with specific representations) and affect student problem-solving skills.

\section{What is the Added Value of Technology Integration in Teaching with MR?}

In recent years, a number of studies at the intersection of MR and the use of computer technologies has been done. A study carried out by Kohnle and Passante (2017) employed a combination of simulation and tutorial to frame physics problems for the purpose of supporting students' representational learning. The study involved 116 university students who enrolled in a physics course in 2016 and 2017. The researchers used similar questions in a pre-test, mid-test, and post-test to assess students' use of representations before, during and after working with a combined simulation and tutorial. The researchers analyzed following students' competencies: (a) the number and types of representations they used; (b) their consistent use of representations; and (c) their levels of representational competence. A secondary purpose of the study was to classify students' responses produced from qualitative reasoning. These responses were summarized in the following three categories: perceptual, syntactic, and semantic. The results of this study showed that the number of the representational formats used by the students and their consistency increased following the instruction which combined the tutorial and simulation, providing support for the value of computational technologies in teaching with MR. Further, based on the distribution of representational competence levels among students the researchers suggest that the students shifted from perceptual use to semantic use of representations.

Other studies also have provided evidence of the value of simulations in teaching with MR. For example, Zacharia and De Jong (2014) conducted a study with the combination of virtual and physical manipulatives. The researchers involved 194 undergraduates in a preservice elementary school teacher program, who enrolled in an introductory physics course. Data were obtained from a conceptual knowledge test on electric circuits, the instructors' reflective journals, video data, and interviews. The researchers used both quantitative and qualitative methods to analyze the data. The quantitative analysis showed that virtual manipulatives were more effective than physical manipulatives in supporting students' conceptual understandings. A possible explanation, as the researchers stated, might be the fact that the virtual manipulatives provided instant feedback. Moreover, the findings of the study revealed that the students in the physical manipulative group had more difficulties in setting up a complex electric circuit than the students who used virtual manipulatives. The findings of these two studies, even though limited in terms of context, provide evidence of the potential of using virtual manipulatives in physics education. Such an approach, as the researchers concluded, offers opportunities for dynamic representations that can be manipulated, as well as opportunities to represent complex phenomena (e.g., electric current) that are not possible to be represented in other ways.

Similar to Zacharia and De Jong (2014), a study conducted by Magana et al. (2019) explored the use of virtual learning environments. Specifically, the researchers investigated which conditions of visual and tactile information can support students' development of learning of force-related concepts. The participants were 170 undergraduate students who enrolled in a physics elementary education class. In a pre- and posttest quasi-experimental design, four groups of students learned with different configurations of multimodal learning environments: (a) visual feedback only; (b) haptic force feedback only; (c) visual and haptic force feedback at the same time; and (d) sequenced modality of haptic feedback first and followed by visual feedback. The haptic feedback was provided through a specific haptic device where the students can use this device extensively in video games. The touch interface used was a joystick, and users were able to manipulate objects on the screen. The results showed that haptic feedback has the potential to support students' conceptual knowledge when compared with visual feedback only. In addition, the use of sequential haptic and visual feedback provides better results on students' post-test scores than the use of simultaneous haptic and visual feedback. A possible explanation for this result is that the use of combined and simultaneous visual and haptic feedback leads to cognitive overload. The findings of this study confirmed that the use of haptic modality is not detrimental to students. Moreover, this study provides evidence of the added value of virtual manipulation (i.e., touch sensory feedback) in the context of science learning.

Hill et al. (2015) examined the use of technology in physics classrooms using an online module. Their study aimed to develop, implement and evaluate the use of 
online learning modules (OLMs), which consisted of some representations. The participants were 400 firstyear physics undergraduate students who randomly engaged either in concept-based OLMs or in representation-based OLMs. Before and after using this module, the participants were asked to fill out a pre- and post-test of conceptual understanding using the Force and Motion Concept Evaluation (FMCE) and the representational survey using Representational Fluency Survey (RFS). The analysis of the data showed that the implementation of the online pre-lecture learning modules resulted in improved learning gains on both conceptual and representational reasoning tests.

Summing up, the findings of these three studies point to the potential value of computer-based MR in supporting students' physics learning such as supporting students' conceptual understandings as well as their representational competence.

\section{SYNTHESIS AND GAPS IN THE LITERATURE}

In synthesizing the existing literature on the use of representations in physics education, one thing becomes clear: representations provide an empowering learning tool that might support university students' understanding of physics concepts, and it is impossible to learn physics without representations. We always need text, formulas, symbols, graphs, and/or figures to learn physics. Overall, the outcomes of the review show that when students use representations in multiple formats during the learning process, their conceptual understandings of physics concepts as well as problemsolving skills are enhanced (Chiou \& Anderson, 2010; Fredlund et al., 2012; Ibrahim \& Rebello, 2013; Kuo et al., 2013; Kohl \& Finkelstein, 2006; Meltzer, 2005). Another set of studies showed that the students face difficulties in switching between different kinds of representations (Bollen et al., 2017; Maries et al., 2017). Lastly, more recent studies provide evidence that technology applications that use MR have the potential to support students' learning (Hill et al., 2015; Kohnle \& Passante, 2017; Magana et al., 2019; Zacharia \& De Jong, 2014). These results can be summarized into the following assertions:

- The use of MR provides an effective learning strategy which can lead to significant improvement of students' conceptual understanding of physics concepts (Opfermann et al., 2017; Treagust et al., 2018).

- The use of diagrams as a form of representation for simple problems might hinder learning because of the added cognitive load placed on the student (Maries \& Singh, 2018; Susac et al., 2019).

- Several teaching models that use MR can be used in the classroom, such as modeling instruction
(McPadden \& Brewe, 2017) and teaching with analogies (Lin \& Chiu, 2017; Podolefsky \& Finkelstein, 2006).

- Different forms of MR might serve different purposes and support the development of specific problem-solving skills (De Cock, 2012; Kohl \& Finkelstein, 2006; Meltzer, 2005; Susac et al., 2018).

- The most commonly faced difficulty by students when engaging with MR is representational fluency, which refers to the ability to switch from one form of representation to another (Chiou \& Anderson, 2010; Ibrahim \& Rebello, 2013).

The outcomes of the literature review also revealed a number of gaps that need to be addressed by future research. These can be summarized into the following:

- The literature does not provide evidence about what forms or combination of forms of representations are more effective than others in physics learning for specific groups of students (for instance, low achievers).

- An understanding of how the students used representations when solving the problems is still missing, as well as how the instructional practice, the classroom environment, the nature of the problems and the students' prior knowledge influence their problem-solving success through the use of different kinds of representations.

- No studies were found that examine: (a) the use (if any) of MR in university textbooks and how those are used by the students; (b) the ways in which the use of MR might support students' development of analogical reasoning; and (c) the use of contemporary technology applications, as for example, augmented and virtual reality in visualizing MR in physics education.

Based on these identified gaps in the literature, in what follows, we propose a research agenda in the area of MR in physics undergraduate education.

\section{FUTURE RESEARCH AGENDA}

\section{Exploring the Use of MR in University Physics Textbooks}

One of the outcomes of this review study is that research related to how physics concepts are represented in physics textbooks is scarce, despite the fact that textbooks are broadly used in physics courses. We argue that such research is important, especially in gaining a better understanding about the ways in which teachers use textbooks. As a matter of fact, Fredlund et al. (2012) argued that the form of representation chosen by students primarily depends on the representations' frequency of use in textbooks and instruction. A related issue is that physics concepts are presented inconsistently and in different representation formats in 
physics textbooks, which might lead to students' development of alternative conceptions (Wong \& Chu, 2017). These alternative conceptions may be identified through an examination of the use of language in the textbooks (Haglund \& Jeppsson, 2012). We argue that this issue needs further investigation. Specifically, we propose that researchers turn their attention to the following questions: (a) What kinds of representations are used to present physics concepts in introductory physics textbooks and how does this affect students' use of representations and conceptual understanding? (b) How do teachers use representations and how does it affect their teaching and students' learning?

\section{Blending of Different Kinds of MR}

In agreement with the arguments put forward by Bollen et al. (2017) and following on the outcomes of this review, we argue that further research is necessary in order to investigate students' difficulties in using MR. We propose that researchers turn their attention to further examining what kinds of representations might be more effective in supporting students to overcome specific difficulties in physics' learning. Hence, it becomes important to examine how MR can be used as input in instructional design and how different forms of representations might be blended (Kohl \& Finkelstein, 2017). Several forms of representations should be considered in order to engage all students to become more effective problem-solvers (Podolefsky \& Finkelstein, 2006). By employing a combination of several representations, students will avoid the weakness of single representations (Ainsworth, 1999). Given that different representations have different functions in learning, we argue for the value of combining them in order to help students obtain better achievements in learning physics. We hence recommend further research that explores the question: how might the blending of several representations support students' conceptual understandings of physics concepts? In order to address this question, the combination or blending of representations should consider the role and function of each representation. Such an approach provides students with opportunities to decide on which representations are most beneficial for them based on their individual needs when they are confronted with several tasks in learning physics.

\section{The Use of Virtual Reality Applications}

For developing a curriculum in physics education, the use of computer technology might play a crucial role in terms of representing complex and abstract physics concepts (Gravel \& Wilkerson, 2017). Advanced technologies, as for example virtual reality, can be used in different ways. Three such ways that have been commonly reported in the literature are the following: (a) to demonstrate virtual experiments that can be manipulated by the students; (b) to communicate students' understanding of a system; and (c) to represent new scientific knowledge. One example of the use of technology in physics education is the Physlet (Cox et al., 2003), which offers three primary advantages: (a) an interactive visualization of abstract concepts; (b) moving beyond problem-solving strategies commonly used by novices; and (c) a quick way to see the effects of changing parameters of different systems. As Kohnle and Passante (2017) argued, the involvement of technology, such as a combination of tutorial and simulation in the learning process affects students' representational competence and helps students understand physics concepts.

In the past few years, the most contemporary technology used in teaching and learning is Virtual Reality (VR), which is defined as "the replication of an environment, achieved by the creation (through specialized hardware and software) of artificial experiences that involve several senses" (Curcio et al., 2017, p. 1). Kaufmann and Meyer (2009) argued that VR is an innovative learning tool that simulates experiments correctly and accurately in physics. As they argued, through VR students can develop virtual models of experiments in order to explore the properties of an object, prove the equations, expand the theory, and actively participate in learning physics. Grounded within such evidence-based arguments and existing (limited) knowledge base (Koutromanos et al., 2015), we recommend that future research is directed towards exploring the following question: In what ways might virtual reality be used to present $\mathrm{MR}$ in order to develop understanding and the ability to use MR, and how can VR applications be embedded in the physics curriculum to facilitate students' learning?

\section{CONCLUSION}

The outcomes of this review study provide evidence that MR can serve as an empowering learning tool in the teaching of physics in university. Moreover, the use of MR can be used as a tool for understanding how students construct and use MR during problem solving and how that process might scaffold students' individual needs. However, we cannot generalize that all kinds of representations can be employed effectively in all physics topics, within all possible learning contexts, and with all students. We maintain that when researchers examine the use of MR during the learning process, they should consider not only the context in which learning takes place and the students, but also how other tools are used, such as textbooks or objects and, of course, the role of the teacher. In closing, what becomes clear in this review study is that there is a growing interest in the use of MR as a learning tool in physics education. What we aimed to do with this review study was to provide an overview of existing knowledge base by synthesizing the findings from studies carried out in different parts of the world about the use of MR at the university level in the past 17 years. 
In doing so, we also identified existing gaps in this knowledge base and we offered a set of concrete recommendations for future research alongside specific research questions. We hope that this paper will serve as a springboard for conversations about the use and value of MR in physics education and for stimulating future research in this developing research area.

\section{ACKNOWLEDGEMENTS}

The authors would like to thank the Islamic Development Bank (IsDB) and the Ministry of Education and Culture of Indonesia for financial support. The content is solely the authors' responsibility and does not necessarily represent the official views of IsDB or the Ministry of Education and Culture of Indonesia.

\section{REFERENCES}

Ainsworth, S. (1999). The functions of multiple representations. Computers and Education, 33(2-3), 131-152. https://doi.org/10.1016/s0360-1315(99) 00029-9

Ainsworth, S. (2008). The Educational Value of Multiplerepresentations when Learning Complex Scientific Concepts. In J. K. Gilbert, M. Reiner, \& M. Nakhleh (Eds.), Visualization: Theory and Practice in Science Education (pp. 191-208). Springer, Dordrecht. https:/ / doi.org/10.1007/978-1-4020-5267-5_9

Bollen, L., Van Kampen, P., Baily, C., Kelly, M., \& De Cock, M. (2017). Student difficulties regarding symbolic and graphical representations of vector fields. Physical Review Physics Education Research, 13(2), 020109. https://doi.org/10.1103/PhysRev PhysEducRes.13.020109

Chen, Z., \& Gladding, G. (2014). How to make a good animation: A grounded cognition model of how visual representation design affects the construction of abstract physics knowledge. Physical Review Special Topics - Physics Education Research, 10(1), 010111. https://doi.org/10.1103/ PhysRevSTPER.10.010111

Chiou, G. L., \& Anderson, O. R. (2010). A study of undergraduate physics students' understanding of heat conduction based on mental model theory and an ontology-process analysis. Science Education, 94(5), 825-854. https:/ / doi.org/10.1002/sce.20385

Cox, A. J., Belloni, M., Dancy, M., \& Christian, W. (2003). Teaching thermodynamics with Physlets® in introductory physics. Physics Education, 38(5), 433440. https:/ / doi.org/10.1088/0031-9120/38/5/309

Curcio, I. D. D., Dipace, A., \& Norlund, A. (2017). Virtual realities and education. Research on Education and Media, 8(2), 60-68. https://doi.org/10.1515/rem2016-0019
De Cock, M. (2012). Representation use and strategy choice in physics problem solving. Physical Review Special Topics - Physics Education Research, 8(2), 020117.

https:/ / doi.org/10.1103/PhysRevSTPER.8.020117

Docktor, J. L., \& Mestre, J. P. (2014). Synthesis of discipline-based education research in physics. Physical Review Special Topics - Physics Education Research, 10(2), 20119. https://doi.org/10.1103/ PhysRevSTPER.10.020119

Fredlund, T., Airey, J., \& Linder, C. (2012). Exploring the role of physics representations: An illustrative example from students sharing knowledge about refraction. European Journal of Physics, 33(3), 657666. https:/ / doi.org/10.1088/0143-0807/33/3/657

Gilbert, J. K. (2010). The role of visual representations in the learning and teaching of science: An introduction. Asia-Pacific Forum on Science Learning and Teaching, 11(1), 1-19.

Gravel, B. E., \& Wilkerson, M. H. (2017). Integrating Computational Artifacts into the Multirepresentational Toolkit of Physics Education. In D. F. Treagust, R. Duit, \& H. E. Fischer (Eds.), Multiple Representations in Physics Education (pp. 47-70). Springer, Cham. https://doi.org/10.1007/978-3319-58914-5_3

Haglund, J., \& Jeppsson, F. (2012). Using self-generated analogies in teaching of thermodynamics. Journal of Research in Science Teaching, 49(7), 898-921. https://doi.org/10.1002/tea.21025

Hill, M., \& Sharma, M. D. (2015). Students' representational fluency at university: A crosssectional measure of how multiple representations are used by physics students Using the representational fluency survey. Eurasia Journal of Mathematics, Science and Technology Education, 11(6), 1633-1655.

https:/ / doi.org/10.12973/eurasia.2015.1427a

Hill, M., Sharma, M. D., \& Johnston, H. (2015). How online learning modules can improve the representational fluency and conceptual understanding of university physics students. European Journal of Physics, 36(4), 045019. https: / / doi.org/10.1088/0143-0807/36/4/045019

Ibrahim, B., \& Rebello, N. S. (2013). Role of mental representations in problem solving: Students' approaches to nondirected tasks. Physical Review Special Topics - Physics Education Research, 9(2), 1-17. https:/ / doi.org/10.1103/PhysRevSTPER.9.020106

Kaufmann, H., \& Meyer, B. (2009). Physics Education in Virtual Reality: An Example. In Themes in Science and Technology Education, 2(1-2), 117-130.

Klein, P., Viiri, J., Mozaffari, S., Dengel, A., \& Kuhn, J. (2018). Instruction-based clinical eye-tracking study on the visual interpretation of divergence: 
How do students look at vector field plots? Physical Review Physics Education Research, 14(1), 10116. https: / / doi.org/10.1103/PhysRevPhysEducRes.14 .010116

Kohl, P. B., \& Finkelstein, N. (2017). Understanding and Promoting Effective Use of Representations in Physics Learning - Multiple Representations in Physics Education. In D. F. Treagust, R. Duit, \& H. E. Fischer (Eds.), Multiple Representations in Physics Education (pp. 231-254). Springer, Cham. https://doi.org/10.1007/978-3-319-58914-5_11

Kohl, P. B., \& Finkelstein, N. D. (2005). Student representational competence and self-assessment when solving physics problems. Physical Review Special Topics - Physics Education Research, 1(1), 010104.

https:/ / doi.org/10.1103/PhysRevSTPER.1.010104

Kohl, P. B., \& Finkelstein, N. D. (2006). Effects of representation on students solving physics problems: A fine-grained characterization. Physical Review Special Topics - Physics Education Research, 2(1), 010106. https://doi.org/10.1103/PhysRevST PER.2.010106

Kohnle, A., \& Passante, G. (2017). Characterizing representational learning: A combined simulation and tutorial on perturbation theory. Physical Review Physics Education Research, 13(2), 020131. https:/ / doi.org/10.1103/PhysRevPhysEducRes.13 .020131

Korff, V. J., \& Rebello, N. S. (2012). Teaching integration with layers and representations: A case study. Physical Review Special Topics - Physics Education Research, 8(1), 010125. https://doi.org/10.1103/ PhysRevSTPER.8.010125

Koutromanos, G., Sofos, A., \& Avraamidou, L. (2015). The use of augmented reality games in education: a review of the literature. Educational Media International, 52(4), 253-271. https://doi.org/ 10.1080/09523987.2015.1125988

Kuo, E., Hull, M. M., Gupta, A., \& Elby, A. (2013). How students blend conceptual and formal mathematical reasoning in solving physics problems. Science Education, 97(1), 32-57. https://doi.org/10.1002/sce.21043

Lehrer, R., \& Schauble, L. (2000). Developing ModelBased Reasoning in Mathematics and Science. Journal of Applied Developmental Psychology, 21(1), 39-48. https://doi.org/10.1016/S0193-3973(99) 00049-0

Lin, J.-W., \& Chiu, M.-H. (2017). Evaluating Multiple Analogical Representations from Students' Perceptions. In D. F. Treagust, R. Duit, \& H. E. Fischer (Eds.), Multiple Representations in Physics Education (pp. 71-91). Springer, Cham. https://doi.org/10.1007/978-3-319-58914-5_4
Magana, A. J., Serrano, M. I., \& Rebello, N. S. (2019). A sequenced multimodal learning approach to support students' development of conceptual learning. Journal of Computer Assisted Learning, 35(4). https://doi.org/10.1111/jcal.12356

Maries, A., Lin, S. Y., \& Singh, C. (2017). Challenges in designing appropriate scaffolding to improve students' representational consistency: The case of a Gauss's law problem. Physical Review Physics Education Research, 13(2), 020103. https:/ / doi.org/ 10.1103/PhysRevPhysEducRes.13.020103

Maries, A., \& Singh, C. (2018). Case of two electrostatics problems: Can providing a diagram adversely impact introductory physics students' problem solving performance? Physical Review Physics Education Research, 14(1), 10114. https://doi.org/ 10.1103/PhysRevPhysEducRes.14.010114

Mathewson, J. H. (1999). Visual-spatial thinking: An aspect of science overlooked by educators. Science Education, 83(1), 33-54. https://doi.org/10.1002/ (SICI)1098-237X(199901)83:1<33::AID-SCE2>3.0. $\mathrm{CO} ; 2-\mathrm{Z}$

McPadden, D., \& Brewe, E. (2017). Impact of the second semester University Modeling Instruction course on students' representation choices. Physical Review Physics Education Research, 13(2), 020129. https:/ / doi.org/10.1103/PhysRevPhysEducRes.13 .020129

Meltzer, D. E. (2005). Relation between students' problem-solving performance and representational format. American Journal of Physics, 73(5), 463-478. https://doi.org/10.1119/1.1862636

Opfermann, M., Schmeck, A., \& Fischer, H. E. (2017). Multiple Representations in Physics and Science Education - Why Should We Use Them? In D. F. Treagust, R. Duit, \& H. E. Fischer (Eds.), Multiple Representations in Physics Education (pp. 1-22). Springer, Cham. https://doi.org/10.1007/978-3319-58914-5_1

Podolefsky, N. S., \& Finkelstein, N. D. (2006). Use of analogy in learning physics: The role of representations. Physical Review Special Topics Physics Education Research, 2(2), 020101. https:/ / doi.org/10.1103/PhysRevSTPER.2.020101

Rosengrant, D., Van Heuvelen, A., \& Etkina, E. (2009). Do students use and understand free-body diagrams? Physical Review Special Topics - Physics Education Research, 5(1), 010108. https://doi.org/ 10.1103/PhysRevSTPER.5.010108

Susac, A., Bubic, A., Kazotti, E., Planinic, M., \& Palmovic, M. (2018). Student understanding of graph slope and area under a graph: A comparison of physics and nonphysics students. Physical Review Physics Education Research, 14(2), 020109. https:/ / doi.org/ 10.1103/PhysRevPhysEducRes.14.020109 
Susac, A., Bubic, A., Martinjak, P., Planinic, M., \& Palmovic, M. (2017). Graphical representations of data improve student understanding of measurement and uncertainty: An eye-tracking study. Physical Review Physics Education Research, 13(2), 020125. https://doi.org/10.1103/PhysRev PhysEducRes.13.020125

Susac, A., Bubic, A., Planinic, M., Movre, M., \& Palmovic, M. (2019). Role of diagrams in problem solving: An evaluation of eye-tracking parameters as a measure of visual attention. Physical Review Physics Education Research, 15(1), 13101. https://doi.org/10.1103/ PhysRevPhysEducRes.15.013101

Sutopo, \& Waldrip, B. (2014). Impact of A Representational Approach on Students' Reasoning and Ceonceptual Understanding in Learning Mechanics. International Journal of Science and Mathematics Education, 12(4), 741-765. https:/ / doi.org/10.1007/s10763-013-9431-y

Treagust, D., Won, M., \& McLure, F. (2018). Multiple representations and students' conceptual change in science. In T. G. Amin \& O. Levrini (Eds.), Converging Perspectives on Conceptual Change (p. 121128). Routledge, London. https://doi.org/10.4324 /9781315467139

Tytler, R., Prain, V., \& Peterson, S. (2007). Representational issues in students learning about evaporation. Research in Science Education, 37(3), 313-331. https://doi.org/10.1007/s11165-006-9028 $-3$

Van Heuvelen, A., \& Zou, X. (2001). Multiple representations of work-energy processes. American Journal of Physics, 69(2), 184-194. https:/ / doi.org/10.1119/1.1286662

Wong, C. L., \& Chu, H.-E. (2017). The Conceptual Elements of Multiple Representations: A Study of Textbooks' Representations of Electric Current. In D. F. Treagust, R. Duit, \& H. E. Fischer (Eds.), Multiple Representations in Physics Education (pp. 183-206). Springer, Cham. https:/ / doi.org/10.1007 /978-3-319-58914-5_9

Zacharia, Z. C., \& De Jong, T. (2014). The Effects on Students' Conceptual Understanding of Electric Circuits of Introducing Virtual Manipulatives Within a Physical Manipulatives-Oriented Curriculum. Cognition and Instruction, 32(2), 101158.

https:/ / doi.org/10.1080/07370008.2014.887083

Zhang, J. (1997). The Nature Problem of External in Solving Representations. Cognitive Science, 21(2), 179-217. https:/ / doi.org/10.1016/S03640213(99)80022-6 


\section{APPENDIX 1}

\section{Overview of the Reviewed Studies}

\begin{tabular}{|c|c|c|c|c|c|}
\hline Authors & Journal & Purpose & Context & Methods & Findings \\
\hline \multicolumn{6}{|c|}{ In what ways does the use of MR in instruction support students' learning? } \\
\hline $\begin{array}{l}\text { Sutopo and } \\
\text { Waldrip (2014) }\end{array}$ & $\begin{array}{l}\text { International } \\
\text { Journal of } \\
\text { Science and } \\
\text { Mathematics } \\
\text { Education }\end{array}$ & $\begin{array}{l}\text { To explore whether a } \\
\text { representational approach could } \\
\text { impact the scores that measure } \\
\text { students' understanding of } \\
\text { mechanics and their ability to } \\
\text { reason }\end{array}$ & $\begin{array}{l}\text { Introductory physics } \\
\text { course in preserve } \\
\text { physics teacher } \\
\text { education; Indonesia }\end{array}$ & $\begin{array}{l}\text { Mixed method - } \\
\text { embedded } \\
\text { experimental } \\
\text { design; pre- and } \\
\text { post-test; } n=24 \\
\text { students }\end{array}$ & $\begin{array}{l}\text { The students' reasoning and } \\
\text { conceptual understanding were } \\
\text { improved after learning with } \\
\text { multiple representations approach }\end{array}$ \\
\hline $\begin{array}{l}\text { Podolefsky and } \\
\text { Finkelstein } \\
(2006)\end{array}$ & $\begin{array}{l}\text { Physical } \\
\text { Review Special } \\
\text { Topics - } \\
\text { Physics } \\
\text { Education } \\
\text { Research } 2\end{array}$ & $\begin{array}{l}\text { To investigate the mechanism of } \\
\text { using analogies and obtain } \\
\text { information whether the } \\
\text { representations from these } \\
\text { analogies have a crucial role in } \\
\text { students' reasoning and } \\
\text { promotion of certain analogical } \\
\text { mapping }\end{array}$ & $\begin{array}{l}\text { Undergraduate } \\
\text { physics course about } \\
\text { electromagnetic } \\
\text { waves; USA }\end{array}$ & $\begin{array}{l}\text { Quantitative } \\
\text { method; large - } \\
\text { scale study of } \\
\text { physics course; } \\
\text { n=602 }\end{array}$ & $\begin{array}{l}\text { There was a correlation between } \\
\text { students' representation choice and } \\
\text { their reasoning ability }\end{array}$ \\
\hline $\begin{array}{l}\text { Susac, Bubic, } \\
\text { Martinjak, } \\
\text { Planinic, and } \\
\text { Palmovic } \\
\text { (2017) }\end{array}$ & $\begin{array}{l}\text { Physical } \\
\text { Review Physic } \\
\text { Education } \\
\text { Research } 13\end{array}$ & $\begin{array}{l}\text { To investigate the influence of } \\
\text { graphical representation of data } \\
\text { on student understanding and } \\
\text { interpreting of measurement } \\
\text { results }\end{array}$ & $\begin{array}{l}\text { Introductory physics } \\
\text { course about } \\
\text { measurement; } \\
\text { Croatia }\end{array}$ & $\begin{array}{l}\text { Quantitative } \\
\text { method; a paper } \\
\text { and pencil test, aye } \\
\text { tracking } \\
\text { measurement; } \\
\mathrm{n}=101\end{array}$ & $\begin{array}{l}\text { The graphical representation can } \\
\text { reduce the load of working memory } \\
\text { and provide a prediction that data } \\
\text { presented in graphical representation } \\
\text { helps students to understand concept } \\
\text { of measurement }\end{array}$ \\
\hline $\begin{array}{l}\text { Rosengrant, } \\
\text { Van Heuvelen, } \\
\text { and Etkina } \\
(2009)\end{array}$ & $\begin{array}{l}\text { Physical } \\
\text { Review Special } \\
\text { Topics - } \\
\text { Physics } \\
\text { Education } \\
\text { Research } 5\end{array}$ & $\begin{array}{l}\text { To investigate why students, use } \\
\text { the representations (free-body } \\
\text { diagrams) and whether those } \\
\text { who use them are more } \\
\text { successful }\end{array}$ & $\begin{array}{l}\text { Physics - based } \\
\text { algebra course about } \\
\text { mechanics; USA }\end{array}$ & $\begin{array}{l}\text { Mixed-method; } \\
\text { multiple-choice } \\
\text { exam and } \\
\text { interview; } n=500\end{array}$ & $\begin{array}{l}\text { The students used free - body } \\
\text { diagram not only for solving the } \\
\text { physics problems but also for } \\
\text { evaluating their work and they get } \\
\text { higher achievement that the students } \\
\text { who did not draw free - body } \\
\text { diagrams }\end{array}$ \\
\hline $\begin{array}{l}\text { Maries and } \\
\text { Singh (2018) }\end{array}$ & $\begin{array}{l}\text { Physical } \\
\text { Review Physi } \\
\text { Education } \\
\text { Research } 14\end{array}$ & $\begin{array}{l}\text { To investigate in which two } \\
\text { different interventions related to } \\
\text { the use of diagrams which were } \\
\text { implemented during recitation } \\
\text { quizzes in a large enrollment } \\
\text { algebra-based introductory } \\
\text { physics course }\end{array}$ & $\begin{array}{l}\text { Algebra - based } \\
\text { introductory physics } \\
\text { course; USA }\end{array}$ & $\begin{array}{l}\text { Quantitative and } \\
\text { qualitative method; } \\
\text { physics problems } \\
\text { quiz and think- } \\
\text { aloud interview; } \\
\mathrm{n}=134\end{array}$ & $\begin{array}{l}\text { The students who provided diagram } \\
\text {; representations spent less time in } \\
\text { understanding and analyzing } \\
\text { physics problems. } \\
\text { The use of diagram representations } \\
\text { in not too complex physics problems } \\
\text { may have a detrimental effect }\end{array}$ \\
\hline
\end{tabular}

Susac, Bubic, Physical To explore the role of supportive Introductory physics Quantitative and The supportive diagrams provided a Planinic, Review Physics diagrams using eye tracking course about energy; qualitative method; positive effect on students Movre, and Education Palmovic Research 15 Croatia

(2019) problem solving physics question and eye tracking measurement; $\mathrm{n}=60$

McPadden and Physical To examine the number and $\quad$ Algebra-based $\quad$ Quantitative $\quad$ There was significant different on

Brewe (2017) Review Physics variety of representations, the introductory physics method; card-short students' achievement between a Education impact of the second semester on course; USA survey in pre- and group of students who already Research 13 students' representation choices, and how students' familiarity with the Modeling Instruction class

Korff and Physical To describe how Amber learned Introductory physics Quc

Rebello (2012) Review Special with a sequence of seven lessons course about method-a case post-semester; employed modeling instruction in $\mathrm{n}=58 \quad$ the previous semester and a group of students who were new with this kind of method

Topics - $\quad$ which facilitate learning of mechanics; USA study; $\mathrm{n}=1$ The use of multiple representations can enhance students' conceptual understanding of physics

Physics integration in physics context

Education

Research 8

\begin{tabular}{|c|c|c|c|}
\hline Klein, Viiri, & Physical & \multicolumn{2}{|c|}{ To investigate the effectiveness of Introductory } \\
\hline Mozaffari, & Review Phy & two strategies involving & undergraduate \\
\hline Dengel, and & Education & representations in enhancing & physics course on \\
\hline Kuhn (2018) & Research 14 & $\begin{array}{l}\text { students' conceptual } \\
\text { understanding }\end{array}$ & $\begin{array}{l}\text { electromagnetism; } \\
\text { Germany }\end{array}$ \\
\hline
\end{tabular}

Quantitative and Two strategies which involved the qualitative method; use of representations (i.e., derivative pre- and post- test, strategy and integral strategy) have interview, and eye their own characteristics to complete tracking each other and provide a positive measurement; $\mathrm{n}=41$ impact on students' understanding of physics concept 


\begin{tabular}{|c|c|c|c|c|c|}
\hline Authors & Journal & Purpose & Context & Methods & Findings \\
\hline \multicolumn{6}{|c|}{ What kinds of representations do students use? } \\
\hline $\begin{array}{l}\text { Kuo, Hull, } \\
\text { Gupta, and } \\
\text { Elby, (2013) }\end{array}$ & $\begin{array}{l}\text { Science } \\
\text { Education }\end{array}$ & $\begin{array}{l}\text { To describe the case that } \\
\text { problem-solving expertise should } \\
\text { include an opportunistically } \\
\text { blending of conceptual and } \\
\text { formal mathematical reasoning } \\
\text { even while manipulating }\end{array}$ & $\begin{array}{l}\text { A calculus - based } \\
\text { d introductory physics } \\
\text { course about } \\
\text { kinematics; USA }\end{array}$ & $\begin{array}{l}\text { Case study; } \\
\text { interview with } \\
\text { physics problems; } \\
\mathrm{n}=13\end{array}$ & $\begin{array}{l}\text { The use of representations such as } \\
\text { blending conceptual and symbolic } \\
\text { reasoning in the problem - solving } \\
\text { process has a potential to support } \\
\text { students' learning physics }\end{array}$ \\
\hline
\end{tabular}

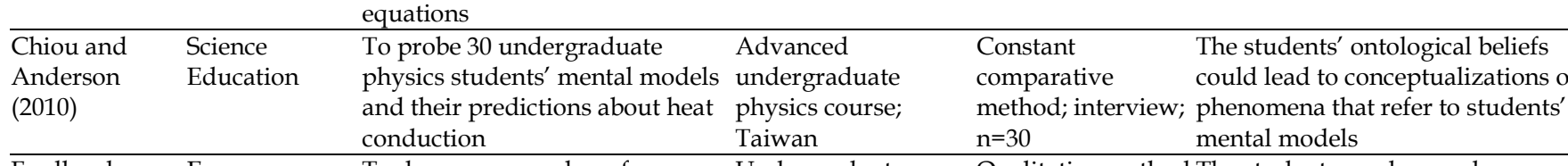

Fredlund, European To draw on a number of sources Undergraduate Qualitative method The students used several

Airey, and Journal of in the literature that explore the physics course on - case study; a representations such as ray

Linder (2012) Physics role of representations in interactive engagement in refraction; Sweden group student physics consisted three students

\begin{tabular}{lll}
\hline Ibrahim and & Physical & To explore the categories of \\
Rebello (2013) & Review Special & mental representations that \\
& Topics - & students work with during \\
& Physics & problem solving of different \\
& Education & representational task formats \\
& Research 9
\end{tabular}

$\begin{array}{lll}\text { A calculus - based } & \text { Qualitative } & \text { Most students used propositional } \\ \text { physics course; USA } & \begin{array}{l}\text { method; problem- } \\ \text { solving task and } \\ \text { interview; } \mathrm{n}=19\end{array} & \begin{array}{l}\text { mental representation when they } \\ \text { dealing with physics problems }\end{array}\end{array}$

What difficulties do students face in using MR?

\section{Bollen, van Physical To describe a study of student} Kampen, Baily, Review Physics difficulties

Kelly and De Education regarding interpreting,

Cock (2017) Research 13 constructing, and switching between representations of vector fields, using both qualitative and quantitative methods

\begin{tabular}{|c|c|c|c|}
\hline $\begin{array}{l}\text { Maries, Lin, } \\
\text { and Singh } \\
(2017)\end{array}$ & $\begin{array}{l}\text { Physical } \\
\text { Review Phys } \\
\text { Education } \\
\text { Research } 13\end{array}$ & $\begin{array}{ll}\text { To investigate student difficulties A calculus - based } \\
\text { s in translating between } & \text { introductory physics } \\
\text { mathematical and graphical } & \text { course about Gauss's } \\
\text { representations for a problem in } & \text { law; USA } \\
\text { electrostatics and find the effect } & \\
\text { of increasing levels of scaffolding } & \\
\text { on students' representational } & \\
\text { consistency } & \end{array}$ & $\begin{array}{l}\text { Qualitative } \\
\text { method; problem- } \\
\text { solving physics } \\
\text { task and think- } \\
\text { aloud interview; } \\
\mathrm{n}=65 \text { (problem- } \\
\text { solving); } \mathrm{n}=7 \\
\text { (interview) }\end{array}$ \\
\hline
\end{tabular}

What is the relation between the use of MR and students' problem-solving ability?

\begin{tabular}{llll} 
What is the relation between the use of MR and students' problem-solving ability? & \\
\hline Kohl and & Physical & To examine student performance Introductory physics Quantitative & There were statistically significant \\
Finkelstein & Review Physics on homework problems given in course; USA & method; problem- performance differences between \\
$\begin{array}{llll}(2005) & \text { Education } & \text { four different representational } & \text { solving physics } \\
& \text { Research } 1 & \text { formats (mathematical, pictorial, } & \text { quizzes and representations of nearly } \\
& & \text { graphical, verbal), and to } & \text { homework; n= } 600 \text { homework problems }\end{array}$
\end{tabular}

examine students' assessment of representations

\begin{tabular}{|c|c|c|c|c|}
\hline $\begin{array}{l}\text { Kohl and } \\
\text { Finkelstein } \\
(2006)\end{array}$ & $\begin{array}{l}\text { Physical } \\
\text { Review Physics } \\
\text { Education } \\
\text { Research } 2\end{array}$ & $\begin{array}{l}\text { To investigate in more detail how Introductory physics } \\
\text { and when student problem- course; USA } \\
\text { solving performance varies with } \\
\text { problem representation, verbal, } \\
\text { mathematical, graphical, or } \\
\text { pictorial. }\end{array}$ & $\begin{array}{l}\text { Qualitative } \\
\text { method; problem- } \\
\text { solving physics } \\
\text { task and interview; } \\
\mathrm{n}=16\end{array}$ & $\begin{array}{l}\text { The form of representations in } \\
\text { presenting physics problems } \\
\text { influence students' problem - } \\
\text { solving skills }\end{array}$ \\
\hline Meltzer (2005) & $\begin{array}{l}\text { American } \\
\text { Journal Physics } \\
73\end{array}$ & $\begin{array}{ll}\text { To analyze the students' } & \text { Algebra - based } \\
\text { problem-solving performance on } & \text { general physics } \\
\text { similar problems posed in } & \text { course; USA } \\
\text { diverse representations } & \end{array}$ & $\begin{array}{l}\text { Quantitative } \\
\text { method- } \\
\text { comparison } \\
\text { between two } \\
\text { representations; } \\
\text { pre- and post-test } \\
\text { and quizzes }\end{array}$ & $\begin{array}{l}\text { There was significant difference of } \\
\text { students' achievement in the } \\
\text { coulomb quiz which used diagram } \\
\text { and graphical representation, but } \\
\text { there is no significant difference } \\
\text { among different representation in } \\
\text { general. }\end{array}$ \\
\hline De Cock (2012) & $\begin{array}{l}\text { Physical } \\
\text { Review Special } \\
\text { Topics - } \\
\text { Physics } \\
\text { Education } \\
\text { Research } 8\end{array}$ & $\begin{array}{ll}\text { To examine student success on } & \text { Undergraduate } \\
\text { three variants of a test item given } & \text { physics course in a } \\
\text { in different representational } & \text { pharmaceutical } \\
\text { formats (verbal, pictorial, and } & \text { science program; } \\
\text { graphical), with an isomorphic } & \text { Belgium } \\
\text { problem statement } & \end{array}$ & $\begin{array}{l}\text { Quantitative } \\
\text { method-a large- } \\
\text { enrollment class; } \\
\mathrm{n}=200\end{array}$ & $\begin{array}{l}\text { The representational format } \\
\text { impacted the students' problem - } \\
\text { solving skills which implies that the } \\
\text { specific, micro - level features of } \\
\text { representation can lead students to } \\
\text { use a particular problem - solving } \\
\text { strategy }\end{array}$ \\
\hline
\end{tabular}


EURASIA J Math Sci and Tech Ed

\begin{tabular}{lll}
\hline \hline Authors & Journal & Purpose \\
\hline Susac, Bubic, & Physical & To study physics and non- \\
Kazotti, & Review Physics physics (psychology) students' \\
Planinic, and & Education & understanding of graphs \\
Palmovic & Research 14 & \\
$(2018)$ & &
\end{tabular}

Context

Methods

Findings

Prospective physics Quantitative and The physics students (graph expert) teachers and qualitative method; had much higher scores than psychology students; $n=90 \quad$ psychology students (non-expert) in Kinematics and finance; USA solving physics problems; physic students solved equally well quantitative and qualitative problems, but psychology students solved qualitative problems better than quantitative problems

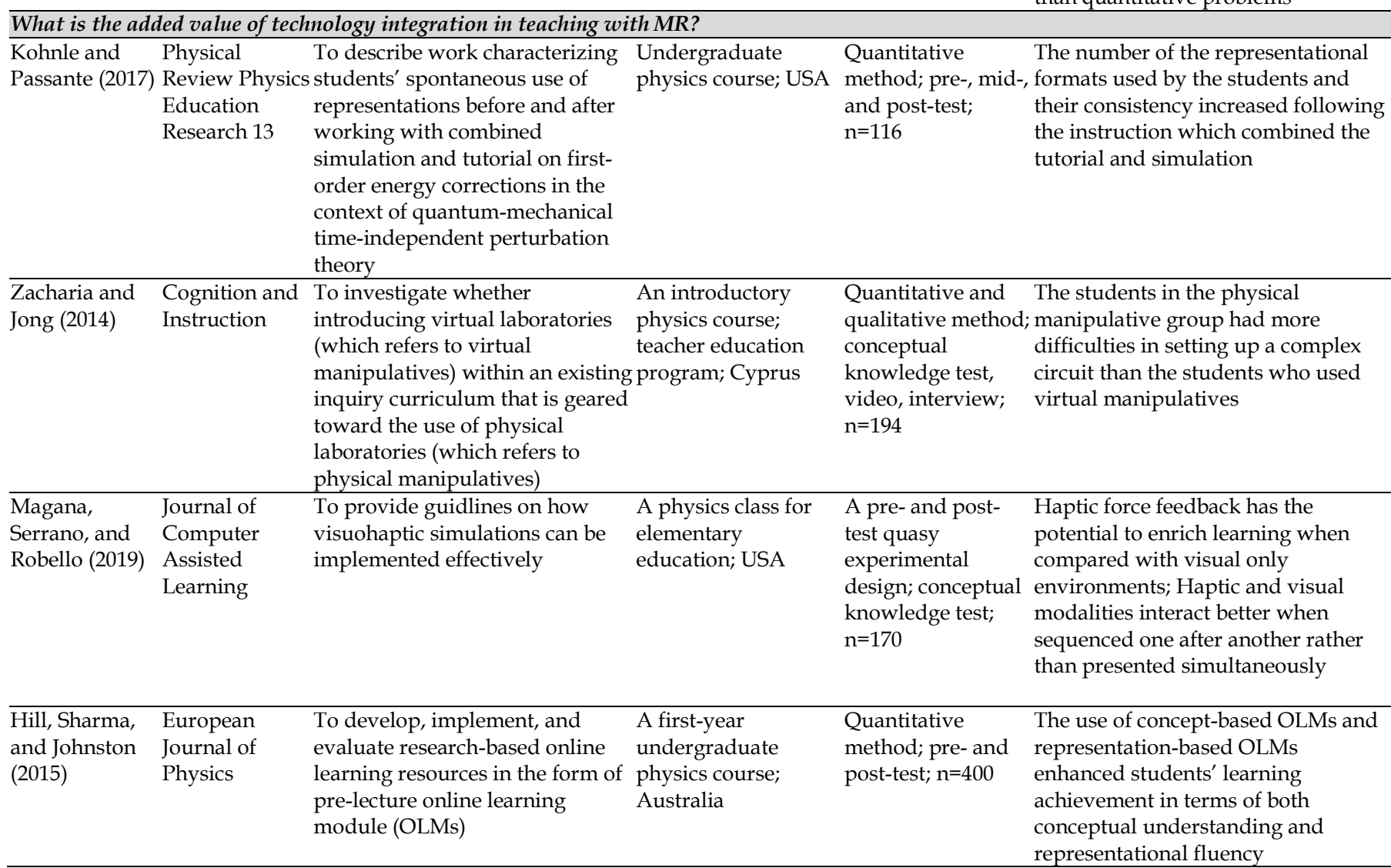

\section{http://www.ejmste.com}

